\title{
Competitive Improvement through Integrated Management of Sales and Operations
}

\author{
Unai Apaolaza ${ }^{1, *(\mathbb{D}}$, Aitor Orue ${ }^{1}$, Aitor Lizarralde ${ }^{1}$ and Aitor Oyarbide-Zubillaga ${ }^{2}(\mathbb{C}$ \\ 1 Mechanics and Manufacturing Department, Mondragon Unibertsitatea, 20500 Mondragon, Spain; \\ aorue@mondragon.edu (A.O.); alizarralde@mondragon.edu (A.L.) \\ 2 Department of Mechanics, Design and Organization, University of Deusto, 48007 Bilbao, Spain; \\ aitor.oyarbide@deusto.es \\ * Correspondence: uapaolaza@mondragon.edu
}

check for

updates

Citation: Apaolaza, U.; Orue, A.; Lizarralde, A.; Oyarbide-Zubillaga, A. Competitive Improvement through Integrated Management of Sales and Operations. Sustainability 2022, 14 , 2722. https://doi.org/10.3390/ su14052722

Academic Editors: José L. Yagüe Blanco and Vanesa Gladys Lo Iacono Ferreira

Received: 3 January 2022

Accepted: 12 February 2022

Published: 25 February 2022

Publisher's Note: MDPI stays neutral with regard to jurisdictional claims in published maps and institutional affiliations.

Copyright: (c) 2022 by the authors. Licensee MDPI, Basel, Switzerland. This article is an open access article distributed under the terms and conditions of the Creative Commons Attribution (CC BY) license (https:// creativecommons.org/licenses/by/ $4.0 /)$.

\begin{abstract}
Several authors agree on the importance of integrating sales and operations (S \& OP) when it comes to improving the management of organisations. Thus, the relationship between $S$ \& OP can be critical from a competitive point of view, and therefore strategic. However, most of the literature on this topic focuses on the field of repetitive manufacturing. Consequently, this work aims to enhance the scarce literature related to S \& OP in organisations that produce make-to-order (MTO). The present study is an analysis of cases of two industrial companies managed according to the theory of constraints. In both cases, the relationship between sales and operations was initially poor. Their approaches were mainly founded on their experience and intuition, as well as on simple data. The development of a new approach, integrating S \& OP, has demonstrated the potential advantages of integrated management. As a result, we have identified some aspects of interest from a managerial perspective. Furthermore, we consider the findings of this study to be relevant to improving the competitiveness of this kind of organisation.
\end{abstract}

Keywords: project management; sales and operations; drum-buffer-rope (DBR); theory of constraints (TOC); demand-driven adaptive enterprise (DDAE); demand-driven MRP (DDMRP)

\section{Introduction}

The evolution of the business environment has led to an increase in both the complexity and competitiveness of organisations [1]. Bennet and Lemoine [2] defined the entrepreneurial space as being volatile, uncertain, complex, and ambiguous (VUCA). In these conditions, adaptiveness to change is an essential quality for companies to survive today. Customer satisfaction is a factor that has acquired growing influence in terms of competitiveness, and three aspects define it: product variety, speed and compliance reliability [3]. To maintain their competitiveness, companies must improve their competence in these for the long term $[4,5]$.

The sustainable enterprise capital management approach [6,7] suggests, "the faster an enterprise achieves and maintains a balance between its capitals" (namely tangibles, financial capital, structural capital, market capital, human capital, and social capital). Consequently, the efficiency of management is a balance between goal achievement efficiency or the "point of balance between capitals" [7]. The authors warn that the search for objectives often hinders the balance between the capitals. So, often, a goal is strived, and only later does the search for the balance between the capitals begin.

The demand-driven adaptive enterprise (DDAE) model arose in response to the VUCA environment to provide a complete model for management [8]. It is composed of three components that together cover operational, tactical, and strategic levels of management. The DDAE approach aims to address all three managerial levels consistently through configuration-feedback-reconciliation cycles, and S \& OP is a key process within this framework. Importantly, DDAE incorporates a flow-based method for the operational 
level: the demand-driven operating model (DDOM). It is aligned with the DDAE approach, aiming at improving ROI performance by protecting and promoting flow.

From this perspective, the sales and operations (S \& OP) approach is an aspect of special interest. Ling and Goddard stated that a consistent connection between the departments of a company, based on aligned overall perspective, might provide significant benefits that could not be achieved separately [9]. Furthermore, to get results, it is essential to address any aspects that might cause organisational misalignments, such as mutually inconsistent incentives or objectives. Organisational alignment is a key component of $\mathrm{S} \& \mathrm{OP}$ that requires understanding and consistency at different levels, functions, and decision areas of an organisation regarding its objectives [10]. Consequently, an advanced $\mathrm{S} \& \mathrm{OP}$ approach can benefit operational management practices [11].

One critical aspect when dealing with supply chains is the type of products to be manufactured. The characteristics of products strongly influence the production approach [12]. Depending on their features, these may be 'functional' (characterised by "stability, predictable demand and low margins") or 'innovative' (signified by "short life cycles, high variety, and more unpredictable demand") [12]. Functional products should be manufactured through efficient supply chains, typically manufacturing-to-stock (MTS). In contrast, responsive supply chains are more suitable for innovative products, which is the case for manufacturing-to-order (MTO) companies. This study addresses the development of $\mathrm{S} \&$ OP capabilities through the DDAE model in two MTO companies that manufacture products on-demand with little or no repeat orders. These companies fall into the MTOVMC (versatile manufacturing companies) category, a context in which simultaneously achieving high levels of productivity and on-time delivery (OTD) is difficult. Being aware of this, the organisations undertook the search for a suitable method. In both cases, the analysis carried out led to the conclusion that the drum-buffer-rope (DBR) method of the theory of constraints (TOC) would meet their needs [13]. However, although they initially considered that the problem was operational, the holistic approach of the TOC opened their eyes. In this way, not only did they start implementing the DBR method, but also oriented the company towards organisational alignment. Thus, both companies embarked on an improvement process framed in the DDAE development path, starting at the first stage of the model.

Nowadays, where the uncertainty and complexity of the market are high, it is crucial to identify good practices to develop competitive advantages. The DDAE experience and results achieved to date constitute a contribution of interest to academics and professionals for several reasons. On the one hand, it shows the itinerary followed by two organisations in their evolutionary process. The experiences from real-world applications help to understand the underlying problems and implications from a holistic point of view. Likewise, the investigation provides practical details on how to address DDAE implementations. Hence, this study is of interest for organisations in general, but especially for MTO organisations. On the other hand, DDAE is a promising but still emerging method. Consequently, the existing literature is very limited. Nevertheless, it is expected that there will be a significant development of the literature in the next few years, as happened with demand-driven material requirements planning (DDMRP) [14]. Consistently with this objective, the application of the DDAE model to VMC organisations contributes to filling the gap in the literature, as there are no reported experiences of application to MTO organisations.

The purpose of this study is to increase and expand knowledge related to the application of the DDAE model, particularly in the context of MTO manufacturing. It is intended to make additional contributions to the existing literature in response to other authors' suggestions, namely conducting more case studies on the application of DBR in the context of MTO [15-17] and developing additional works based on integrated approaches to the problem, beyond the typical perspective based exclusively on cost and benefit parameters [18]. To this end, we describe the transformation process at two boiler-making VMC companies within the framework of the DDAE model. The research compiles the journey of both companies from the initial situation to the first results obtained within $S$ \& OP, 
covering steps 1 to 3 of the DDAE development path. In brief, it involved rethinking their production models, adopting a DDOM based on DBR, and consistently aligning the organisations towards overall objectives through the S \& OP approach.

The present research consists of two case studies and a cross-case analysis. The implementation of DDAE in both organisations is analysed first. Then a cross-case analysis of the cases is carried out. To facilitate understanding, the structure follows the three stages of the DDAE development path. The remainder of this paper is arranged as follows: Section 2 provides the theoretical background of this study. Section 3 explains the objectives and research methodology. The individual case studies conducted are reported in Section 4. Section 5 is a cross-case analysis developed stage by stage. Finally, Section 6 summarises the conclusions and limitations of the research and suggests directions for further study.

\section{Theoretical Background}

The current complexity of the market has been defined as VUCA in the introduction. Organisations must adapt to this new reality, requiring suitable approaches. The DDAE model is a clear example of this. It is a recently created model born in the VUCA context which aims to provide a comprehensive response to the present needs of organisations. The S \& OP approach is one of the fundamental aspects of the DDAE framework when it comes to integrating the different levels of organisations. The potential for improving the competitive position offered by DDAE depends significantly on the proper adoption of the $\mathrm{S} \& \mathrm{OP}$ approach. Organisational alignment is an essential aspect in this regard, which turns particularly complex in the case of MTO organisations, the subject of this inquiry. This section analyses the theoretical background of the concepts involved in the present study.

\subsection{The DDAE Model}

The DDAE model arose in response to the VUCA environment to provide a complete model for management [8]. It is composed of three components that together cover the operational, tactical, and strategic levels of management, namely the demand-driven operating model (DDOM), demand-driven sales and operations planning (S \& OP), and adaptive sales and operations planning (see Figure 1). The DDAE approach aims to address all three managerial levels consistently through configuration-feedback-reconciliation cycles. Relevant ranges for management and relevant information are crucial to the model $[8,19]$. Management strongly depends on the timely availability of information, and distortions to this information may hamper the effective management of the system.

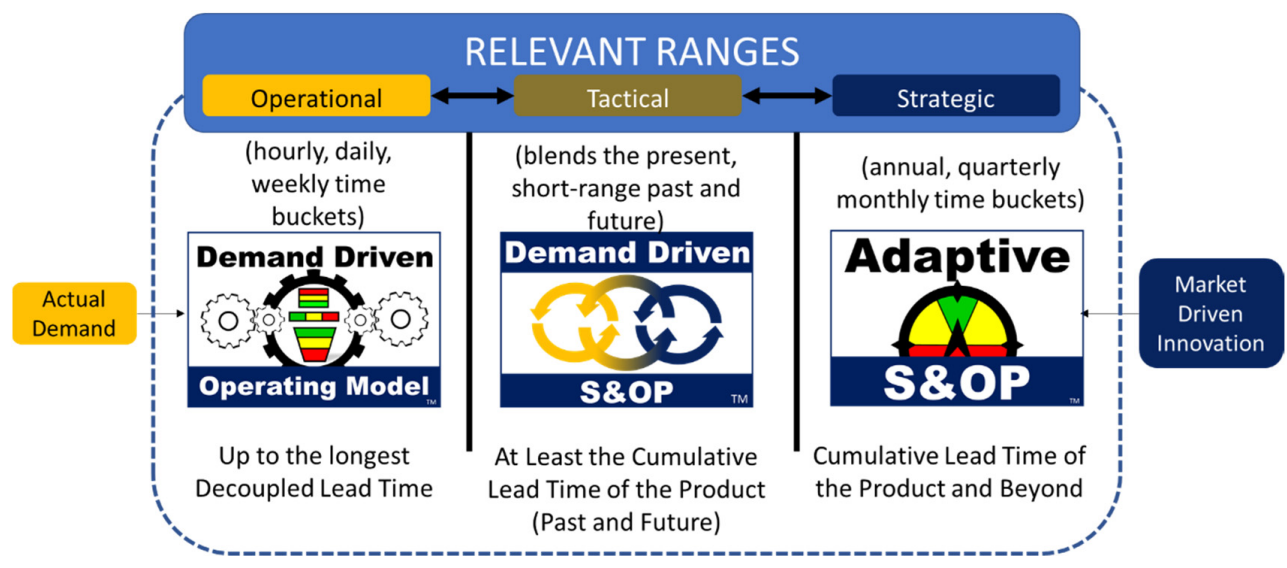

Figure 1. DDAE model and relevant ranges definitions (Figure 7-1, p. 156). Reprinted with permission from Ref. [8]. Copyright 2018 Industrial Press, Inc. 
Ptak and Smith [8] define four prerequisites to relevant information, emphasizing that all of them are needed for this purpose: understanding relevant ranges, tactical reconciliation between relevant ranges, a flow-based operating model, and a flow-based metrics suite. These prerequisites are briefly described below:

- Understanding relevant ranges mean that assumptions are valid within suitable periods. Consequently, assumptions and relevant information related to different ranges may differ significantly. This is the case for the operational, tactical, and strategic ranges.

- The relevant ranges must be continuously and iteratively reconciled. Thus, when dealing with the strategy, a company must consider its operational capability and performance. By the same token, the strategy influences the operational capability. Finally, to reconcile the operational and the strategic ranges, the tactical range must operate bi-directionally.

- A flow-based operating model aims at protecting and promoting flow. From this perspective, flow can be a unifying factor not limited to operations but also between functions.

- To support a flow-based operating model, a company must adopt suitable metrics for each one of the relevant ranges. Those metrics must be reconcilable between ranges. In this way, such metrics should assist the company in maintaining organisational consistency and controlling variability.

In the context of DDAE, work carried out by people who are consistently aligned is referred to as collaboration [8]. The DDAE model adopts the following definition for $\mathrm{S} \& \mathrm{OP}$, which is a key process within its framework [11] (p. 154):

"A process to develop tactical plans that provide management the ability to strategically direct its businesses to achieve competitive advantage on a continuous basis by integrating customer-focused marketing plans for new and existing products with the management of the supply chain. The process brings together all the plans for the business (sales, marketing, development, manufacturing, sourcing and financial) into one integrated set of plans. It is performed at least once a month and reviewed by management at an aggregate (product family) level".

The DDOM effectively links the actual demand and S \& OP, the tactical range of the DDAE model [8]. In other words, it matches the operational capability and the strategic requirement. Thus, it generates real-time signals based on the actual demand. The DDOM strongly depends on DDMRP, "A method to model, plan and manage supply chains to protect and promote the flow of relevant information and materials. DDMRP is the supply order generation and management engine of a demand driven operating model" [20]. The three components of the DDMRP are demand-driven MRP, demand-driven scheduling, and demand-driven execution [14].

The key aspects of each stage are summarised below:

- $\quad$ Stage 1 is typically the starting point for most companies. In this context, the managerial approach to maximising overall results is mainly focused on minimising costs and maximising resource usage. The flow concept is neglected or even ignored.

- $\quad$ Stage 2 is the first step to becoming a demand-driven company. The aim is to enhance overall performance. The main operational driver is flow, orientated towards enhancing OTD. The concepts, criteria, and metrics of stage 2 are not compatible with those of stage 1. Consequently, the move to the second stage entails a change in methodology, which in turn implies a change in their way of thinking.

- $\quad$ Stage 3 is the first step towards a demand-driven organisation. It requires DDOM to be fully implemented, and its focus is on improving flow performance based on a tactical analysis beginning with $S$ \& OP.

- The aim of stage 4 is to "Leverage the DDOM capability across the enterprise and into the market". Thus, the entire organisation must understand it from an overall perspective.

- Stage 5 deals with adapting and improving the organisational capabilities of the organisation facilitating the flow between the participants in the supply chain. 
The model defines a five-stage implementation path to guide companies through the progressive adoption process (see Figure 2).

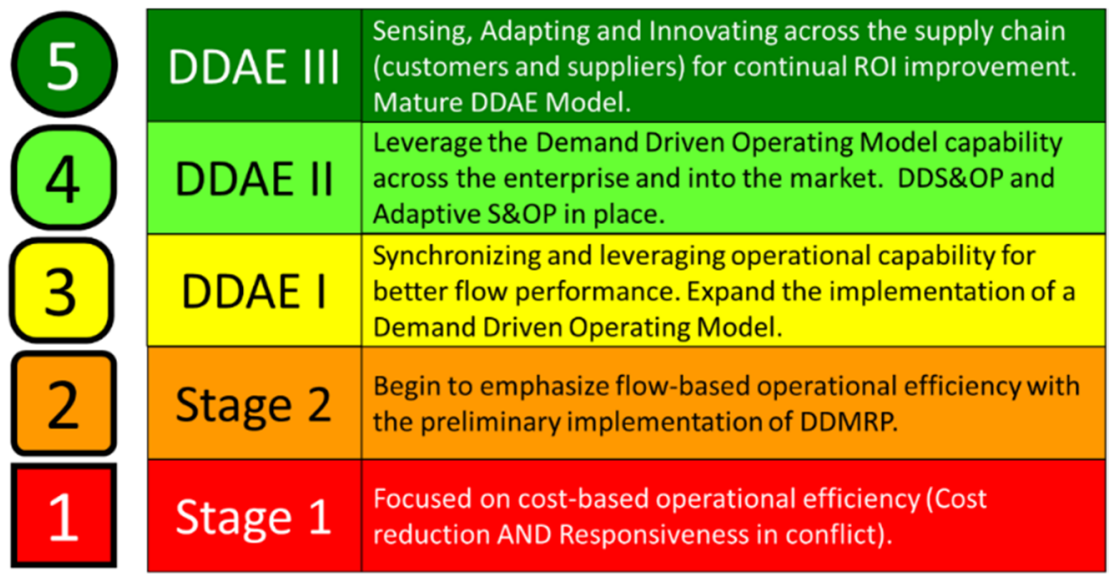

Figure 2. The DDAE development path. Reprinted with permission from Ref. [21]. Copyright 2022 Demand Driven Institute.

\subsection{The $S$ \& OP Approach}

$\mathrm{S} \& \mathrm{OP}$ is a key process within a company that aims at reconciling the market demand and the production capacity [22]. Within this framework, companies consistently develop the plans they need at different decision levels; thus, they typically cover a period of up to the next eighteen months [23]. According to the traditional view, the objective of S \& OP is to respond to the market demand efficiently (i.e., in terms of cost, time, and quality) [24]

Conceptually, S \& OP has been around for many years, even though little was published about it until relatively recently [25]. Although Singhal and Singhal [26] placed the origins of S \& OP in the 1950s, the term itself was developed in the 80s [9]. Its originators suggested that a consistent connection between the departments of a company, based on aligned overall perspective, might provide significant benefits that could not be achieved separately. Importantly, they highlighted the necessity to address any aspects that might cause organisational misalignments, such as mutually inconsistent incentives or objectives.

Traditionally, the areas of a company directly involved in supply chain management (procurement, production, distribution, and sales) have worked independently, and organisational misalignment has resulted in consequences across businesses [27]. Organisational misalignment occurs when the different functions of a company pursue distinct objectives [28]. As a result, different viewpoints influence their decisions and behaviour. Organisational alignment is a key component of $S$ \& OP that requires understanding and consistency at different levels, functions, and decision areas of an organisation regarding its objectives [29]. Thus, the adoption of an advanced S \& OP decision support system can benefit operational management practices [18]. Performance measurement is a critical aspect to success within S \& OP [30-32]. From this perspective, some authors claim that sometimes the objective should include other parameters beyond the traditional cost/profit optimisation, such as service level [18] or OTD performance [33]. Thus, the need for specific and mutually consistent supply chain metrics has been identified as a necessary aspect that can improve the integration of the different functions of the organisation, thereby contributing to increasing organisational alignment.

The issue of reaching an integrated response has spurred interest [1]. Several authors agree that it can significantly enhance organisational performance [18,23,27]. Guo et al. [10] reported the influence of cross-functional integration on a company's performance, stating that it was critical for different performance dimensions across an organisation. From this standpoint, Kathuria, Joshi, and Port [29] emphasised the significance of positioning when implementing strategies, which "is fostered by aligning and adjusting key systems, 
processes and decisions within the firm". They explained that organisational alignment could be vertical (involving the various levels of a company) or horizontal (being crossfunctional and intra-functional). They concluded that organisational alignment requires a consistently integrated approach. Grimson and Pyke [25] focused on the potential of combining operations and sales, suggesting that the impact of an integrated vision combining these two functions could be more significant when factoring in the benefits of operational cost reductions and revenue growth from sales, respectively.

The context of the application is another relevant aspect within the S \& OP framework, as it may lead to diverse results and consequences. Olhager, Rudberg, and Wikner roughly describe $S \& O P$ as a sales plan and a production plan, which must be balanced [34]. Deviations between sales and production plans will be reconciled in different ways depending on the production approach. Thus, the mechanism to compensate deviations in MTS companies is stock, whereas in the case of MTO firms a backlog plan will be required. As organisations must have proper capacities to cover the demanding needs of the market, planning is a crucial issue. Stadtler and Kilger [35] established three levels of planning within the $S$ \& OP view, considering the importance of decisions and the corresponding time horizons: long-term, medium-term, and short-term. The long-term corresponds to the strategic level, concerning the decisions regarding the future of the supply chain. Consequently, the time horizon covers several years. The medium-term deals with the planning of flows and resources at an aggregate level, over a horizon that can range from a few months to a year. Finally, the operational level focuses on the short term (days or weeks), considering execution and control at a detailed level.

Since it was coined, S \& OP has evolved across different stages until the present day, transcending the intra-organisational scope [36]. The basic S \& OP design described in handbooks $[9,37]$ can be applied in most organisational contexts. However, the detailed design depends on the context because the specific problem that $S$ \& OP must solve may differ between contexts, as different $S \& O P$ designs may be required to solve the same type of problem in different contexts. [38] The overall S \& OP problem has not been characterised in one single model $[18,38]$. On the contrary, the cases reported in the literature deal with partially integrated approaches or with specific cases. On the other hand, S \& OP has been developed by practitioners to a large extent [25]. Despite the growth of academic literature about this subject during recent years, gaps between industry needs and academic research still exist [30]. Several authors claim new approaches capable of dealing with integrated management within the $S \& O P$ framework. For example, Pereira suggests developing new procedures that allow the integration of other decisions into the models [18]. The literature evidences the high level of correspondence between the overall S \& OP view and the DDAE model. Section 2.1 demonstrates that the foundations of the DDAE model are in line with this perspective. Importantly, flow, ranges (i.e., strategic, tactical, and operational), and metrics are noteworthy in both views. All this justifies the interest in developing DDAE model implementation case studies, to contribute to the development and expansion of the literature on the subject.

\subsection{MTO}

MTS typically manufacture a small variety of products in high quantities with short delivery times. Inventory usually plays a key role in this type of environment [39], in a way that allows the purchase and manufacture of products to begin before an order is placed [40]. As defined by Amaro, Hendry, and Kingsman [41], for MTO manufacturing, orders are placed for basic designs. Customisation is a key feature, and manufacturing begins after an order is generated. Consequently, it is not possible to accurately forecast demand for products that are manufactured only after a customer's order is confirmed. In terms of purchasing, only raw materials or components that are regularly used can be purchased in advance and stored. It means that the use of inventory as an aid for production management [39] is limited and highly dependent on the characteristics of each case. MTO companies can either be repeat business customisers (RBCs) or versatile manufacturing 
companies (VMCs) [41]. RBC companies produce customised products that are ordered and produced more than once. Compared to RBCs, VMCs produce a wider variety of products with little or no repeat orders. Thus, the characteristics of VMC organisations make it very difficult to achieve high levels of productivity and OTD simultaneously [42].

The environment in which MTO companies operate is becoming increasingly complex [43]. To increase competitiveness, these organisations must increase their OTD reliability. It involves improving their efficiency throughout the entire order-delivery process, especially to the customer inquiry stage [40]. Typically, MTO companies adopt a job shop arrangement to manufacture a wide variety of products in small quantities. It is consistent with their reactive approach. In other words, the ability to adapt to customer needs in terms of flexibility, quality, and OTD is essential to be competitive in MTO contexts $[1,44]$

There are clear parallels in multi-projects and MTO, especially considering the difficulties in managing resources for simultaneous activities. There are clear parallels in multi-projects and MTO, especially considering the difficulties in managing resources for simultaneous activities. Thus, an organisation must deal efficiently with the activities required to reach its objectives [45]. Tenhiäla and Ketokivi [46] analysed operational MTO performance and focused on product customisation, order management, and operational performance. They found that managerial practices and information processing were very different depending on the level of customisation required, concluding that the use of certain project management (PM) practices was important when dealing with high levels of customisation. Furthermore, several attempts to apply the PM approach to MTO have been reported in the literature, given the similarities between the two [45].

\section{4. $D B R$}

The companies analysed decided to implement DBR, the TOC production management method [13]. DBR pursues comprehensive management of the production system focused on its constraint(s), called the drum. According to this perspective, the drum must govern the system. The drum's production program is developed to meet the organisation's needs, and the rest of the system is subordinated to this plan. The rope is the link between the production program and the entrance to the process. This way, the materials are timely supplied to the system following the overall priorities. Finally, a buffer protects the drum against variability. The buffer is a part of the program produced before its need date in the drum. The availability of materials at this point guarantees the on-time supply of the necessary orders to the drum, consequently allowing it to work non-stop.

The DBR approach is consistent with the DDAE-DDOM perspective [44]. DDOM is based on DDMRP, and one of the underlying foundations of DDMRP is TOC. Thus, although DDMRP is suitable for organisations that work with stock, the DDOM is equally valid for other types of organisations, such as MTOs. As materials management lacks prominence in the case of MTO-VMC organisations, DDMRP cannot be applied regularly. The focus should be on manufacturing order management. As a result, in MTO-VMC contexts only two of the three components of DDMRP are relevant: demand-based scheduling and demand-based execution.

\section{Materials and Methods}

\subsection{Objectives and Research Methodology}

The capital goods sector is of great importance in the Basque country. There are many MTO-VMC SMEs, and the boiler-making industry is of particular interest. The study of the literature has revealed the lack and the need for additional bibliography. Thus, this study aims to deepen practical knowledge of the application of the DDAE model in this industry.

The definition of the unit of analysis and the case selection process are keys to the case study method. In this study, the unit of analysis was the company, and case selection was based on three criteria:

- Manufacturer firms were selected from the Basque country.

- We chose MTO-VMC firms. 
- $\quad$ The companies had to be engaged in the capital goods sector.

Each of the previously stated three criteria was verified before the execution of the cases. Other practical issues, such as the willingness to participate and accessibility, were also considered. The case companies have similar sizes, production processes and skills. However, the characteristics of their products are different and involve significant differences from the production point of view. These differences mainly concern the management of production capacity, delivery times, and costs. Hence, we believe that the analysis of both cases provides a broad overview of the essential aspects of this context.

Given the characteristics of this inquiry, we chose to conduct it using the action research (AR) methodology [47]. Consequently, the research is addressed through an approach largely applied in the field of operations management [48]. AR is a variant of case study research, in which a researcher is directly involved in their research activities [49-51]. The very nature of the DDAE model (see Figure 1) requires activities to be organised based on configuration-feedback-reconciliation cycles to progressively pass levels, which adequately fits the AR approach developed by Coughlan and Coghlan [50]. It is summarised in Figure 3. Furthermore, observations obtained from both academics and practitioners are part of this work [52-54]. A brief description of the stages in the particular context of this research is provided below:

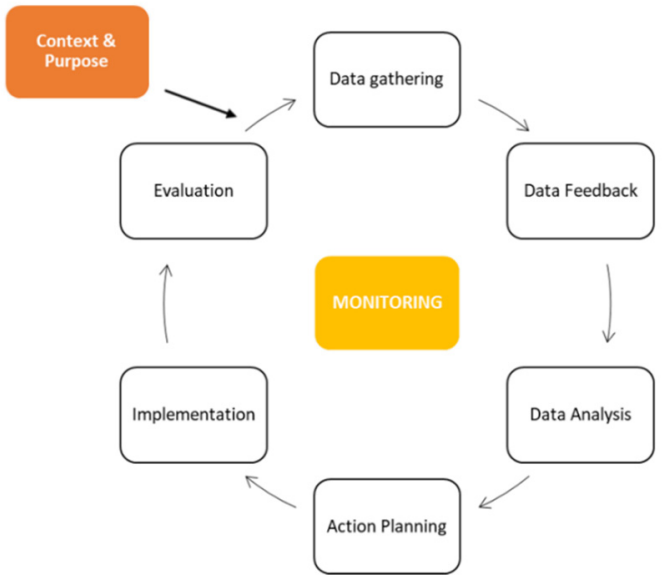

Figure 3. AR cycle.

Adapted with permission from Ref. [50]. 2002 Emerald Publishing Limited.

- Context and purpose: the researchers, in collaboration with the managers and the key functions involved, conducted an initial analysis for each company. As a result, both companies decided to launch an implementation project and develop their implementation plans. The general approach was based on a weekly meeting of the implementation team. Key members of the company and researchers composed the implementation team. Depending on the new needs, the assistance of additional participants or different sessions was occasionally required.

- Data gathering: the researcher, as a participant, directly observed and accessed data and information. The main information sources were participant observation, documents, and software.

- Data feedback: the data and information available were reported to the company (typically every week) and shared with other researchers involved in the study.

- Data analysis: it was conducted regularly, in collaboration with the company (typically every week). The joint data analysis enables combining the practitioners' know-how and the theoretical knowledge of the researchers. Thus, the appropriateness of the data for the case was guaranteed. 
- Action planning: definition, prioritisation, and planning of actions to be deployed and implemented. This part was influenced by both resource availability and the response of the software supplier.

- Implementation: execution of the actions defined in the previous point as defined in the plan.

- Evaluation: assessment of the progress of the action plan to get an overall picture of the situation, as well as data and information valuable for the next cycle.

- Monitoring: this meta-step looked for a timely and precise perspective of on-going actions and the overall progress. Initially, the approach was mainly based on the weekly meeting. However, at stage 2 a monthly meeting was also implemented to analyse overall results and look for improvements and opportunities. Apart from the implementation team, the foremen and the key employees involved in the $\mathrm{S} \& \mathrm{OP}$ participate in this meeting.

This study focuses on corporate transformation carried out by two boiler-making companies in Spain's Basque country. Both companies began this journey at the lowest level of the DDAE model; thus, they have developed new capabilities as they have progressed through the model. This analysis is based on two-year observation periods at each organisation. The details are discussed in the next section.

\subsection{Case Studies}

The cases analysed in this study share several common features. Both companies are industrial boiler makers that manufacture products for other organisations. Their process begins with their customers providing a specification for their orders. The companies then complete the engineering work (design plans and bills of materials) and the materials purchasing and production, which may vary depending on the characteristics of the product. The implications of these features will be detailed in each case.

OTD is an important aspect of the boiler-making industry. Both companies were aware of this and tried to orientate themselves towards it. However, neither of them achieved a consistent and efficient managerial approach. Each section of their businesses was managed almost autonomously, causing purchasing and production orders to be placed as soon as they were available. In addition, they were driven by 'productivity and cost-orientated metrics' (e.g., minimising the hours needed to complete each manufacturing order). This approach typically led to the companies reaching both high levels of productivity and low overall OTD service levels-far below the expectations of their respective managers.

After disappointing results had continued over time, the companies decided to conduct studies to improve their performance. They found that their approach to production had been strongly based on local criteria. This caused misaligned practices that conflicted with their main objective (i.e., high level of service). Consequently, the organisations decided to undertake organisational change. Firstly, they adopted an operational model based on the DBR approach. After implementing and adjusting to their new approach, they continued to implement an integrated managerial approach, framed on the DDAE model (see Figure 1). At the time this study was developed, both organisations had taken their first steps into stage 3 of the DDAE development path. The case studies in Section 4 analyse the stage-by-stage progression of the companies. The results of the case studies are discussed in Section 5 based on a cross-case analysis.

\section{Results}

\subsection{Case 1}

Company 1 designs and manufactures customised large structures in small batches (often unitary). Its acquisition of raw materials strongly influences delivery times, which may vary considerably depending on the characteristics of the materials ordered. Thus, the delivery time for one product typically ranges from 1 to 6 months. In addition, one order may comprise several deliveries and take more than a year to complete. 


\subsubsection{Stage 1: Operational Efficiency-Cost}

The initial underlying criterion in batch manufacturing is economical. It assumes that producing larger batches will result in better purchasing prices and fewer hours spent on completing orders. In other words, the company was expected to improve productivity and costs, thereby achieving better overall results.

An initial assessment uncovered several unexpected factors. Furthermore, it was revealed that the organisation was not even aware of the consequences of its decisions. First, minimising the hours required to complete an order entailed placing all manufacturing orders that were necessary for completion. A customer order might comprise one or more manufacturing orders, each one associated with a specific delivery date (progressive deliveries). Consequently, once the corresponding manufacturing orders were placed, large volumes of semi-finished products would build up, consuming more capacity than was needed at that moment. In addition, these capacity peaks often required additional capacity to meet internal milestones, which necessitated overtime or the use of subcontractors. Finally, from the perspective of service, the impact on workflow was negative. Only the first order progressed continuously until completion. The rest of the orders remained stuck in the process for a long time, obstructing and hindering the workflow. In brief, while the productivity level of each section was high, overall OTD performance was poor.

\subsubsection{Stage 2: Operational Efficiency-Flow}

The DDOM shown in Figure 4 was applied in response to the problems posed in the previous section. The heart of the system was the job shop, managed through the DBR approach and focusing on the strategic drum (i.e., the process of machining). The drum was protected against uncertainty by the drum buffer (a time buffer), which gave the programme reliability and stability. The post-drum processing was handled similarly by another checkpoint (C2) and the shipping buffer (also a time buffer), which was located between the end of the production process and shipment to protect shipment dates.

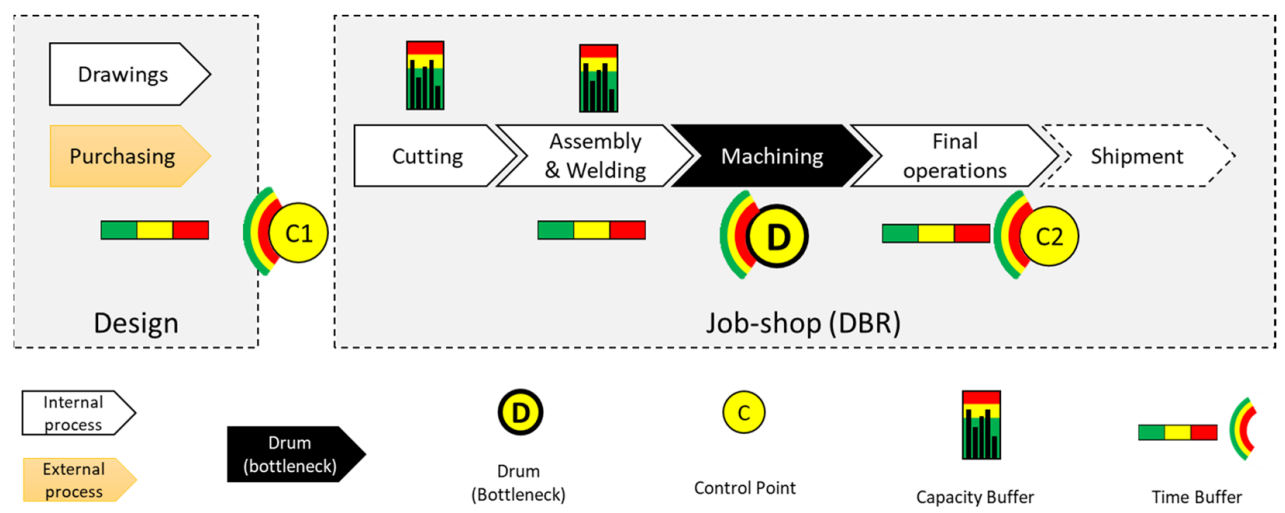

Figure 4. The demand-driven operating model implemented in Case 1. Note: The control point C1 connects the design and production (job shop) processes. The drum D limits the capacity of the entire system and sets the overall production rate. Both $\mathrm{C} 1$ and $\mathrm{D}$ are decoupling points protected with time buffers.

The rest of the system was organised around the DBR within the DDOM and the DDAE frames, as shown in Figure 1. The design department provided drawings and bills of materials to the job shop. The $\mathrm{C} 1$ control point managed the connection between the design and production (job shop) stages. This was another decoupling point with its corresponding time buffer, which contributed to the timely delivery of documentation and materials.

The progressive development and implementation of the model involved a deep change in the mindset of the company. This enabled it to move from a cost-based approach to one that was flow-based in design, purchasing, and job shop activities. The new approach 
also provided multiple advantages from a managerial perspective. Planning, programming, and reporting became easier, enabling permanent updating of data and information. Thus, the system provided clear visibility based on priorities at all levels, aligned towards the overall objective. Furthermore, the time buffers provided protection against uncertainty, making the system more predictable and stable. In addition, the margin of capacity available in non-buffer resources enhanced the reactivity of the company. As a result, the time previously spent reacting to emergencies and unexpected situations was significantly reduced, thereby facilitating better system management.

The information reported by the company proved that results had been significantly improved. The flow-related results over the period observed were 100\% OTD and 10\% average lead-time reduction. Other metrics were also improved, namely $20 \%$ less work in process, $20 \%$ fewer purchase orders in progress, $25 \%$ fewer manufacturing orders in progress, $40 \%$ less material in the job shop and 20\% fewer quality issues. The company also reported that although there had been an increase in working hours during the processes preceding the bottleneck, these were accomplished at regular capacity.

\subsubsection{Stage 3: Approaching the DDAE}

After the DDOM was established, the performance level of the organisation was monitored over time, with a focus on the main metrics. The global performance and stability levels reported were significantly higher than in past results. Furthermore, the better results were sustained over time, confirming that the DDOM had led to an improved overall performance. However, occasional situations that altered the company's performance were reported. Problems that originated outside the operational model were identified, such as order commitment dates sometimes causing workload peaks and valleys, challenging the operational capabilities of the DDOM and thereby reducing its performance. When discussing this issue with the sales department, it was discovered that the department's main metric - its monthly sales figures-had had a significant impact on the system. This metric was directly linked to the annual sales objective, which sought to achieve the necessary sales to meet the company's annual objective.

In this way, the monthly figure determined the result for the period, while the accumulated annual figure provided an aggregate view of the year. Hence, this indicator was exclusively economic and had no relationship whatsoever with capacity or time. Under these conditions, the sales department lacked the motivation to coordinate sales within the organisation's capabilities. Besides, neither this indicator nor any other information had warned of such problems. As a result, the distribution of the resulting workload made the organisation's aligned management difficult, as by not considering the time factor, the sales generated significant disorders in the production system. In summary, the target monthly sales indicator had been a source of misalignment in the system that had a direct impact on the DDOM's performance, making evident the need to align the different components of the organisation beyond the DDOM.

\subsection{Case 2}

In the case of Company 2, standard raw materials could be acquired in one or two weeks, and orders were completed in three or four weeks. The work lasted a few days at each stage (sometimes even hours). Thus, this operational scenario was significantly more dynamic than in Case 1.

\subsubsection{Stage 1: Operational Efficiency-Cost}

The organisation's approach was to start work on jobs as soon as possible, in the belief that doing so would contribute to compressing schedules. Section managers would then aim to reconcile resource utilisation with delivery dates. However, the study carried out led to similar conclusions to Case 1, proving that this approach was counterproductive. Placing orders as soon as possible increased work in progress (WIP), thereby making it difficult to manage each manufacturing section. The metrics, orientated towards local productivity 
enhancement, led managers to prioritise orders with the highest chance for fast completion (i.e., those with the greatest materials availability). On the other hand, jobs were assigned to maximise the number of tasks running simultaneously. Finally, the only time reference was the order delivery date, which turned into the only order prioritisation criterion.

The feeling was that the combination of these criteria would enhance each department's productivity, thereby improving the overall result. However, an assessment showed that such an improvement was an illusion. Delivery date was found not to be a valid criterion for priority management at the operational level. The very nature of each job determined the time required, and the delivery date did not provide significant information for decision making at the section level. Furthermore, the WIP made work management more difficult, especially in terms of priorities. Likewise, maximising the number of on-going activities entailed longer deadlines, as the concentration of resources had been minimised. In summary, the initial approach resulted in good local results alongside poor overall results, proving the ineffectiveness of the previous model and the existence of organisational misalignment.

\subsubsection{Stage 2: Operational Efficiency-Flow}

The same approach used in Case 1 was also applied here. Hence, the DDOM was similar to the previous model (see Figure 5), in that the heart of the system was the drum schedule, which was managed through DBR. It was the basis for setting the priorities for the rest of the organisation, which were updated every day with the assistance of the information system. Compared to Case 1, the main differences were:

- The drum was the assembly welding resource (in Case 1, it was the process of machining).

- Once the job shop works were completed, some external operations were still required. The post-DBR processes were subordinated based on overall needs as in the design process. The control point $\mathrm{C} 2$ connected the job shop and the post-DBR activities, managing deliveries to external operation suppliers.

- Two additional control points managed post-DBR activities consistently with the delivery dates: $\mathrm{C} 3$ controlled the flow of incoming orders from the external operation suppliers, whereas C4 managed the timely assembly and shipment of orders.

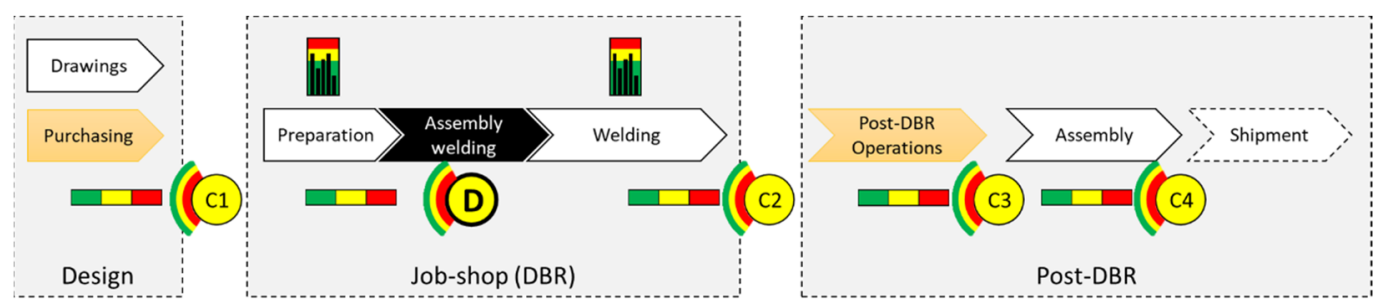

Figure 5. The demand-driven operating model implemented in Case 2. Note: The approach, representation, and symbols for Case 2 are the same as in Case 1. The control point $\mathrm{C} 1$ connects the design and production (job shop) processes. The drum limits the capacity of the entire system and sets the overall production rate. The control point $\mathrm{C} 2$ connects production (job shop) and post-DBR external processes. $\mathrm{C} 1, \mathrm{C} 2$, and the drum are decoupling points protected with time buffers. Post-DBR operations and final assembly are managed through control point C3.

Once the software was fully available, the managers became aware of the advantages of the approach. As in Case 1, tasks related to planning, programming and reporting were easier and the information provided by the system proved to be valuable for managing various areas of the company. Thus, the company obtained highly accurate and valuable information that provided unprecedented visibility. Furthermore, in the early stages of implementation, everything seemed to point to a general improvement in the organisation's performance. Nevertheless, the preparation of the system for use coincided with the outbreak of the COVID-19 pandemic. A substantial drop in sales made it impossible 
to work within conditions suitable for testing the full capabilities of the system in real conditions. Thus, there are not yet any conclusive results available.

Nevertheless, the system was tested and adjusted for different situations as the market recovered. It worked as expected, although workload conditions were still below normal levels. It was found that the method aligned the different sections with the global objectives, reaching promising performance results. Furthermore, the system behaved very similarly to that in Case 1. Thus, even though additional tests in full-load conditions are still required, we do not see any reason to think that it would not work properly.

The result of the assessment carried out from a managerial perspective is highly coincident with Case 1 . The new model has aligned reliably the entire organisation towards its main objective, which is OTD. The key is to promote flow through suitable use of resources by focusing on the appropriate priorities. Moreover, this approach is coherent and manageable both at general and local levels (i.e., company and section or department). The DBR program set the dates and priorities in the buffer reliably and the priorities for the rest of the organisation unfolded accordingly.

The availability of information was a critical aspect, and the information system was a key component for getting valuable and updated information. This allowed resources to be managed according to the necessary priorities and adapted to the real circumstances of each moment (e.g., availability of materials). Another important matter was the need to adapt to changing conditions. The inherently short lead times of the orders caused this context to be very dynamic; thus, it required frequent monitoring and continuous decision making. Consequently, it was necessary to hold daily coordination meetings between managers.

As a result of the work carried out, the managers highlighted that their organisation had significantly increased its reactivity. Besides, the early results made evident the need for a means to get answers systematically. Thus, the company initiated a tactical analysis of the new model to gain wider alignment beyond the operational level. Despite the delicate market conditions caused by the pandemic, the system was ready.

\subsubsection{Stage 3: Approaching the DDAE}

Due to the dynamic, monitoring the key points of the system over time was prioritised to determine the coherence of the operational and tactical fields based on objective information. Thus, as the system was ready, the tactical analysis of the new model was launched despite the unusual market conditions caused by the pandemic. The main metric defined to determine system performance was the level of service, complemented with program compliance at the control points. These metrics enabled the identification of critical points and non-compliance causes. The main findings of this stage are as follows:

- The main problems identified were supply delays and overly short customer delivery times that were often impossible to meet. Both problems were rooted in the unique market situation, which was expected to be transitory.

- Internal processes did not generate delays in addition to those caused by supplies. On the contrary, supply delays were often totally or partially recovered by the internal operations.

- The welding process (immediately after the drum) proved to be more efficient than the preparation processes (immediately before the drum).

- When the materials were supplied on time, the drum program compliance level was close to $100 \%$.

The results seem to confirm that the system met the requirements of the process for which it was defined. The data collected indicate that the time buffers and the capacities defined were suitable. Likewise, the information system demonstrated its ability to generate timely information that was necessary to manage the system under the model.

\section{Discussion}

This analysis is framed in the DDAE model. To facilitate reading, the essential aspects of each implementation experience are organised according to the phases of the model. 


\subsection{Stage 1}

The suspicion that their performance had been below potential prompted both companies to seek to improve their capabilities. In both cases, this situation resulted in an external assessment. This enabled the companies to identify reasons why their performance was below potential and caused them to miss their objectives. The assessment revealed that their previous processes were based on local perspectives, with cost minimisation being the main underlying criterion. It led to practices such as grouping purchase and manufacturing orders into batches to keep costs and manufacturing time to a minimum or maximise resource utilisation. The performance measures were also consistent with this vision and favoured and encouraged these practices. However, they were found to penalise other aspects that had not been identified until that point, and whose impact had not been correctly assessed. The main objective, OTD, was the most affected aspect. But other negative consequences, such as unnecessary storage costs or limited cash flow, were also identified.

Another interesting finding was that PM might assist in identifying deviations. Due to their background and how they had developed, both organisations lacked a PM culture and practices. Consequently, by the time the deviations had been identified, it was too late. However, the analysis also revealed that even if they had detected the deviations earlier, they would hardly have been able to react on time. The existing metrics and organisational misalignment would have made it impossible to articulate a suitable response. In brief, the result of the diagnosis made the companies aware of the impact of their organisational misalignment.

\subsection{Stage 2}

The assessment led the organisations to change their operational approach, moving from a cost-based operational model to a flow-based one. They adopted a DDOM based on DBR and were inspired by the DDAE model, which had proven its effectiveness. The control points enhanced the control capabilities of the system and the buffers protected performance against uncertainty. Beyond improving operational results, the DDOM provided substantial advantages from a managerial perspective. First, it enabled the alignment of different sections of the company, consistently with the overall objectives. The DBR approach generated a program for the bottleneck, and the rest of the system was arranged accordingly. This approach is simple and provides stability to the system. Besides, the information system now gives daily updated priorities at all operational levels of the organisation. This information enhances visibility both from both manufacturing (operational) and managerial (customer order/PM) perspectives.

The metrics have proven to be crucial for the implementation of the DDOM. The availability of suitable metrics (i.e., consistently aligned towards the global objective) served for both the purposes of measurement and as an alignment enabler. The metrics strongly influenced how activities were addressed, and, consequently, the decision making and processes. By the same token, when the metrics were not aligned with each other and the main objectives, they become a source of organisational misalignment. This was proven by the radically different results achieved within the same contexts.

Moving from a cost-based perspective to a flow-based model involved a deep change of corporate mindset for both companies. The change process took months and involved several learning sessions and discussions until the key people in the companies were able to assimilate the concepts. From this perspective, the words of the CEO of Company 2 were especially interesting. He acknowledged that initially, he had not fully understood the implications of flow orientation, but due to the need to improve, he decided to believe in it. Indeed, the involvement of key managers enabled the effective transformation from a cost-optimisation-based approach to a flow-based approach for the entire company. The CEO explained the change as follows: "Previously, each department was dedicated to maximising its productivity and focusing on its objectives. Now we ask ourselves these questions: how can I contribute to meeting the global deadline? Where does the company's 
problem lie today? What can I do to help solve it?" These questions summarise the new logic of the system after the DDOM had been implemented.

Interestingly, the first stages of the DDAE model are based on DDOM and DDMRP. In some cases, it may be enough to manage a company at an operational level. Nevertheless, in most cases, a scheduling approach is also required. That is the case for MTO-VMC companies. Given their special characteristics, stock buffers are inexistent, or at best, residual. In contrast, the other components of the DDMRP approach (i.e., control points and buffers) became particularly important to provide the reactiveness levels required.

\subsection{Stage 3}

The implementation of the DDOM enabled both companies to identify their true potential, including both their capabilities and limitations. From that point onwards, other limitations preventing the companies from achieving better overall results also became evident. These limitations transcended the operational scope, making them difficult to identify across the previous stage. The DDAE model then guided the organisations into the $S$ \& OP realm. However, although both companies used the same DDAE model, they proceeded in different directions because of the different characteristics of their businesses.

The long average order lead-times of Company 1 made it crucial to have long-term capacity management, which involved the sales department. The metrics and objectives related to this issue had to be reviewed and corrected, with significant changes made to sales procedures that required coordination with manufacturing. In contrast, the short lead times that characterised Company 2 required more reactiveness. Improving reactiveness involved enhanced dynamic capabilities, especially when it came to information availability and decision making. The information system was endowed with more features to respond to new needs, and manufacturing management was reinforced with daily coordination meetings to address issues that required a greater level of detail.

In summary, it can be concluded that the initial objectives of both organisations were achieved through stage 2 of the DDAE model. Furthermore, beyond the attainment of their operational objectives, entry into stage 3 was an eye-opener for both organisations, which now see greater development potential and a clear itinerary.

\section{Conclusions, Limitations, and Future Research}

\subsection{Conclusions}

The results of this inquiry imply that the management of MTO-VMC activities must integrate the various visions of the system. In MTO-VMC, organisational alignment is crucial for high overall performance levels to be reached. To achieve organisational alignment, it is necessary to take a systemic approach, as an integration level limited to operations may be insufficient for this purpose. Furthermore, the individual perspectives of the different parts of a company may be sources for organisational misalignment. The $S$ \& OP perspective goes beyond the operational context, allowing for improved performance. It requires higher levels of integration and alignment, which also entail further complexity and difficulty. The literature stresses the difficulties of putting into practice the implementation of an S \& OP approach. The DDAE model has proven to be an adequate guide for this purpose. The five stages of the model facilitate the understanding and preparation of the transitions between stages.

Managing a VMC requires consistent integration and subordination of the components of a company to its overall goals. Specifically, it involves integrating the perspective of resource utilisation with deadline control (PM perspective). Regarding resource utilisation, it is essential to coordinate design/engineering and production activities within the overall framework. This results in different objectives and strategies if compared to those generated from individual procedures. Likewise, orders are typically addressed as projects. The objectives and plans that result from the project-planning process can also be a source of organisational misalignment if they are not properly integrated within a 
common framework. In other words, the project approach and the operational capabilities of the system must be coordinated.

\subsection{Limitations and Future Research}

Finally, this study has two main limitations. First, the case studies analysed belong to the MTO-VMC context in the boiler-making sector. Consequently, to strengthen our findings and confirm their potential for expansion, additional case studies are required in other contexts. On the other hand, the scope of the studies carried out is limited to the first three stages of the DDAE model. Additional studies completing other phases would increase the knowledge related to its potential and applicability. Therefore, we invite other researchers to carry out additional work in this direction.

Author Contributions: Conceptualisation, U.A., A.O., A.L. and A.O.-Z.; methodology, U.A. and A.O.-Z.; software, U.A.; validation, U.A., A.O., A.L. and A.O.-Z; formal analysis, U.A. and A.L.; investigation, U.A., A.O., A.L. and A.O.-Z.; resources, U.A.; data curation, U.A.; writing-original draft preparation, U.A., A.O., A.L. and A.O.-Z.; writing-review and editing, U.A., A.O., A.L. and A.O.-Z.; visualisation, U.A.; supervision, U.A., A.O., A.L. and A.O.-Z.; project administration, U.A.; funding acquisition, U.A. All authors have read and agreed to the published version of the manuscript.

Funding: This research received no external funding.

Institutional Review Board Statement: Not applicable.

Informed Consent Statement: Not applicable.

Data Availability Statement: Restrictions apply to the availability of these data. Data were obtained from the case companies and are available from the authors with the permission of the case companies.

Conflicts of Interest: The authors declare no conflict of interest.

\section{References}

1. Wang, Z.; Qi, Y.; Cui, H.; Zhang, J. A Hybrid Algorithm for Order Acceptance and Scheduling Problem in Make-to-Stock/Maketo-Order Industries. Comput. Ind. Eng. 2019, 127, 841-852. [CrossRef]

2. Bennett, N.; Lemoine, G.J. What a Difference a Word Makes: Understanding Threats to Performance in a VUCA World. Bus. Horiz. 2014, 57, 311-317. [CrossRef]

3. Jaegler, Y.; Jaegler, A.; Burlat, P.; Lamouri, S.; Trentesaux, D. The ConWip Production Control System: A Systematic Review and Classification. Int. J. Prod. Res. 2018, 56, 5736-5757. [CrossRef]

4. Borreguero-Sanchidrián, T.; Pulido, R.; García-Sánchez, Á.; Ortega-Mier, M. Flexible Job Shop Scheduling with Operators in Aeronautical Manufacturing: A Case Study; IEEE Access: Piscataway, NJ, USA, 2018; Volume 6, pp. 224-233. [CrossRef]

5. Romagnoli, G. Design and Simulation of CONWIP in the Complex Flexible Job Shop of a Make-To-Order Manufacturing Firm. Int. J. Ind. Eng. Comput. 2015, 6, 117-134. [CrossRef]

6. Klimek, D. Sustainable Enterprise Capital Management. Economies 2020, 8, 12. [CrossRef]

7. Klimek, D.; Jedrych, E. A Model for the Sustainable Management of Enterprise Capital. Sustainability 2021, 13, 183. [CrossRef]

8. Ptak, C.; Smith, C. The Demand Driven Adaptive Enterprise Model; Industrial Press, Inc.: South Norwalk, CT, USA, 2018; ISBN 9780831136352.

9. Ling, R.C.; Goddard, W.E. Orchestrating Success: Improve Control of the Business with Sales E Operations Planning; Oliver Wight Limited Publications: Dallas, TX, USA, 1988; ISBN 0939246112.

10. Guo, L.; Tobias, J.; Bendoly, E.; Hu, Y. Different Departments, Different Drivers: Asymmetry in Antecedents and Outcomes of Voluntary Knowledge Exchange between Sales and Production Functions. Int. J. Oper. Prod. Manag. 2017, 37, 1031-1053. [CrossRef]

11. APICS. APICS Dictionary: The Essential Supply Chain Reference, 14th ed.; Blackstone, J.H., Ed.; APICS Publication: Chicago, IL, USA, 2013; ISBN 098821461X.

12. Fisher, M.L. What Is the Right Supply Chain for Your Product? Harv. Bus. Rev. 1997, 75, 105-117.

13. Goldratt, E.M.; Cox, J.F. The Goal: Excellence in Manufacturing; North River Press: Croton-on-Hudson, NY, USA, 1984.

14. Maylor, H.; Turner, N.; Murray-Webster, R. “It Worked for Manufacturing ... !": Operations Strategy in Project-Based Operations. Int. J. Proj. Manag. 2015, 33, 103-115. [CrossRef]

15. Rabbani, M.; Tanhaie, F. A Markov Chain Analysis of the Effectiveness of Drum-Buffer-Rope Material Flow Management in Job Shop Environment. Int. J. Ind. Eng. Comput. 2015, 6, 457-468. [CrossRef]

16. Thürer, M.; Stevenson, M.; Silva, C.; Qu, T. Drum-Buffer-Rope and Workload Control in High-Variety Flow and Job Shops with Bottlenecks: An Assessment by Simulation. Int. J. Prod. Econ. 2017, 188, 116-127. [CrossRef] 
17. Pereira, D.F.; Oliveira, J.F.; Carravilla, M.A. Tactical Sales and Operations Planning: A Holistic Framework and a Literature Review of Decision-Making Models. Int. J. Prod. Econ. 2020, 228, 107695. [CrossRef]

18. Ptak, C.; Smith, C. Precisely Wrong: Why Conventional Planning Systems Fail; Industrial Press, Inc.: South Norwalk, CT, USA, 2017; ISBN 0831136189.

19. Demand Driven Institute. The Official DDI Dictionary. Available online: https://www.demanddriveninstitute.com/dictionary (accessed on 6 February 2022).

20. Ptak, C.; Smith, C. Demand Driven Material Requirements Planning (DDMRP); Industrial Press Incorporated: South Norwalk, CT, USA, 2016; ISBN 9780831135980.

21. Demand Driven Institute. The DDAE Development Path. Available online: https://www.demanddriveninstitute.com/demanddriven-adaptive-enterprise-m (accessed on 12 February 2022).

22. Olhager, J.; Johansson, P. Linking Long-Term Capacity Management for Manufacturing and Service Operations. J. Eng. Technol. Manag. 2012, 29, 22-33. [CrossRef]

23. Feng, Y.; D'Amours, S.; Beauregard, R. The Value of Sales and Operations Planning in Oriented Strand Board Industry with Make-to-Order Manufacturing System: Cross Functional Integration under Deterministic Demand and Spot Market Recourse. Int. J. Prod. Econ. 2008, 115, 189-209. [CrossRef]

24. Nabil, L.; el Barkany, A.; el Khalfi, A. Sales and Operations Planning (S \& OP) Concepts and Models under Constraints: Literature Review. Int. J. Eng. Res. 2018, 34, 171-188.

25. Grimson, J.A.; Pyke, D.F. Sales and Operations Planning: An Exploratory Study and Framework. Int. J. Logist. Manag. 2007, 18, 322-346. [CrossRef]

26. Singhal, J.; Singhal, K. Holt, Modigliani, Muth, and Simon's Work and Its Role in the Renaissance and Evolution of Operations Management. J. Oper. Manag. 2007, 25, 300-309. [CrossRef]

27. Thomé, A.M.T.; Scavarda, L.F.; Fernandez, N.S.; Scavarda, A.J. Sales and Operations Planning: A Research Synthesis. Int. J. Prod. Econ. 2012, 138, 1-13. [CrossRef]

28. Schmenner, R.W.; Swink, M.L. On Theory in Operations Management. J. Oper. Manag. 1998, 17, 97-113. [CrossRef]

29. Kathuria, R.; Joshi, M.P.; Porth, S.J. Organizational Alignment and Performance: Past, Present and Future. Manag. Decis. 2007, 45, 503-517. [CrossRef]

30. Noroozi, S.; Wikner, J. Sales and Operations Planning in the Process Industry: A Literature Review. Int. J. Prod. Econ. 2017, 188, 139-155. [CrossRef]

31. Smith, D.; Smith, C. Demand Driven Performance: Using Smart Metrics; McGraw Hill Education: New York, NY, USA, 2014; ISBN 0071796096

32. Smith, D. The Measurement Nightmare: How the Theory of Constraints Can Resolve Conflicting Strategies, Policies, and Measures; CRC Press: Boca Raton, FL, USA, 2000; ISBN 1574442465.

33. Tuomikangas, N.; Kaipia, R. A Coordination Framework for Sales and Operations Planning (S \& OP): Synthesis from the Literature. Int. J. Prod. Econ. 2014, 154, 243-262. [CrossRef]

34. Olhager, J.; Rudberg, M.; Wikner, J. Long-Term Capacity Management: Linking the Perspectives from Manufacturing Strategy and Sales and Operations Planning. Int. J. Prod. Econ. 2001, 69, 215-225. [CrossRef]

35. Stadtler, H.; Kilger, C. Supply Chain Management and Advanced Planning: Concepts, Models, Software, and Case Studies; Springer: Berlin, Germany, 2008; ISBN 978-3-540-74511-2.

36. Olhager, J. Evolution of Operations Planning and Control: From Production to Supply Chains. Int. J. Prod. Res. 2013, 51, 6836-6843. [CrossRef]

37. Wallace, T.; Stahl, B. The Demand Planning Process in Executive S \& OP. J. Bus. Forecast. 2008, 27, 19.

38. Kristensen, J.; Jonsson, P. Context-Based Sales and Operations Planning (S \& OP) Research: A Literature Review and Future Agenda. Int. J. Phys. Distrib. Logist. Manag. 2018, 48, 19-46. [CrossRef]

39. Jones, T.C.; Riley, D.W. Using Inventory for Competitive Advantage through Supply Chain Management. Int. J. Phys. Distrib. 1985, 15, 16-26. [CrossRef]

40. Soman, C.A.; van Donk, D.P.; Gaalman, G. Combined Make-to-Order and Make-to-Stock in a Food Production System. Int. J. Prod. Econ. 2004, 90, 223-235. [CrossRef]

41. Amaro, G.; Hendry, L.; Kingsman, B. Competitive Advantage, Customisation and a New Taxonomy for Nonmake-to-stock Companies. Int. J. Oper. Prod. Man. 1999, 19, 349-371. [CrossRef]

42. Darlington, J.; Francis, M.; Found, P.; Thomas, A. Design and Implementation of a Drum-Buffer-Rope Pull-System. Prod. Plan. Control 2015, 26, 489-504. [CrossRef]

43. Manikas, A.; Gupta, M.; Boyd, L. Experiential Exercises with Four Production Planning and Control Systems. Int. J. Prod. Res. 2015, 53, 4206-4217. [CrossRef]

44. Sultana, I.; Ahmed, I. A State of Art Review on Optimization Techniques in Just in Time. Uncertain Supply Chain Manag. 2014, 2, 15-26. [CrossRef]

45. Babu, A.S. Strategies for Enhancing Agility of Make-to-order Manufacturing Systems. Int. J. Agil. Man. 1999, 1, 23-29. [CrossRef]

46. Tenhiälä, A.; Ketokivi, M. Order Management in the Customization-responsiveness Squeeze. Decis. Sci. 2012, 43, 173-206. [CrossRef]

47. Lewin, K. Action Research and Minority Problems. J. Soc. Issues 1946, 2, 34-46. [CrossRef] 
48. Handfield, R.B.; Melnyk, S.A. The Scientific Theory-Building Process: A Primer Using the Case of TQM. J. Oper. Manag. 1998, 16, 321-339. [CrossRef]

49. Benbasat, I.; Goldstein, D.K.; Mead, M. The Case Research Strategy in Studies of Information Systems. MIS Q. 1987, 11, 369-386. [CrossRef]

50. Coughlan, P.; Coghlan, D. Action Research for Operations Management. Int. J. Oper. Prod. Manag. 2002, 22, 220-240. [CrossRef]

51. Platts, K.W.; Mills, J.F.; Bourne, M.C.; Neely, A.D.; Richards, A.H.; Gregory, M.J. Testing Manufacturing Strategy Formulation Processes. Int. J. Prod. Econ. 1998, 56-57, 517-523. [CrossRef]

52. Lewis, M.W. Iterative Triangulation: A Theory Development Process Using Existing Case Studies. J. Oper. Manag. 1998, 16, 455-469. [CrossRef]

53. McCutcheon, D.M.; Meredith, J.R. Conducting Case Study Research in Operations Management. J. Oper. Manag. 1993, 11, $239-256$. [CrossRef]

54. Van Aken, J.; Chandrasekaran, A.; Halman, J. Conducting and Publishing Design Science Research: Inaugural Essay of the Design Science Department of the Journal of Operations Management. J. Oper. Manag. 2016, 47, 1-8. 